\title{
A Multi-Frame Analysis Of For-Profit Higher Education
}

\author{
Matthew R. Hodgman, Goodwin College, USA
}

\begin{abstract}
After years of remarkable expansion, the for-profit higher education sector is showing signs of an industrial reset in the wake of increased federal regulations aimed at addressing claims of aggressive recruiting practices and high student default rates throughout the sector. Large publicly-traded for-profit universities, such as the University of Phoenix, have resultantly experienced precipitous drops in student enrollment. As an initial point to begin thinking about for-profit higher education going forward, this article will put forth a multi-frame organizational analysis of the University of Phoenix with the particular goal of generating a body of knowledge endemic to improving Phoenix's overall operating environment and discussing the important role the school has played and can continue to play in (re)defining higher education in the United States. This discussion can be used as an entry point to promulgate further discussion surrounding significant issues in for-profit higher education and the changing landscape of higher education.
\end{abstract}

Keywords: University of Phoenix; For-Profit Higher Education; Reframing Organizations

\section{INTRODUCTION}

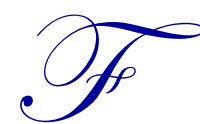

or-profit colleges (FPCs) enroll over three million students in a wide variety of vocational and more traditional certificate and degree programs. Between 1986 and 2009, the popularity of FPCs grew from $2 \%$ of all students to more than $10 \%$ of all students enrolled in institutions of higher education (Liu, 2011). With the need for workers to possess new skill sets and credentials in an increasingly global economy, the demand for degrees and certificates offered by FPCs has never been greater. FPCs are institutions of higher education that are run by private, profit-seeking companies or organizations. These schools heavily depend on federal student aid dollars to survive. During the 2008-2009 school year, students at FPCs received \$4.3 billion in Pell grants and \$20 billion in federal loans - an increase in federal student aid funds of $109 \%$ between 2005 and 2009 alone (Liu, 2011). With rapid growth came increased scrutiny of the for-profit sector. FPCs were accused of employing questionable recruiting practices and students have often defaulted on their student loans or failed to graduate. The average student default rate at FPCs is $25 \%$ compared to $10.8 \%$ at public colleges and $7.6 \%$ at private non-profit colleges (Liu, 2011).

These points raise questions as to how FPCs conduct business and what their students are getting out of a for-profit education. On a basic level, FPCs attract more non-traditional students, typically students who attend parttime, work full time while enrolled, have dependents other than a spouse, may have a GED instead of a high school diploma, and delay enrollment until years after graduating high school. With high student loan default rates, low graduation rates, and low job placement rates compared to their more traditional higher education brethren, are FPCs actually hurting the students they purport to help?

FPCs are certainly curious players in higher education today. There has been criticism against FPCs claiming they do not help students achieve their academic and career goals (Chait, 2011; Hacker \& Dreifus, 2010; Liu, 2011; Wilson, 2010; Yeoman, 2011). The Department of Education has proposed several regulations to protect students from aggressive or misleading recruiting practices at FPCs and to provide consumers with better information about the effectiveness of proprietary programs. Some of the more stringent regulatory proposals involve meeting specific benchmarks for loan repayment and debt-to-earnings ratios in order for students to remain eligible for federal student aid (Liu, 2011). As a result of these regulations, for-profit colleges and universities have experienced sharp declines in student enrollment (Gavett, 2011). 
Within this climate, the University of Phoenix (Phoenix) managed to rise to national prominence in a relatively short period of time. Phoenix was founded in 1976 by John Sperling, a tenured professor at San Jose State University, as an organization dedicated to helping adult students. Since then, Phoenix has become national in scope with its enrollment four times that of the next for-profit competitor. As for-profit higher education expert Dr. Kevin Kinser (2006) points out, with nearly 400,000 students and counting, campuses in nearly 40 states, and a standardsetting online presence, Phoenix is clearly the national leader in for-profit education (2006). Phoenix is owned by the Apollo Group which has a market value around $\$ 9$ billion - at least $\$ 2$ billion greater than its nearest publiclytraded competitor, the Washington Post Company (Kinser, 2006).

Despite these clear financial and growth indicators, what most noticeably sets Phoenix apart from the rest of the for-profit sector may be its unconventional academic model. Most FPCs do not offer tenure, hold national accreditation, or offer classes that are directed toward independent learners. Phoenix offers tenure, is regionally accredited, grants doctoral degrees, and practically created the centralized short semester-block curriculum model in for-profit education; this model has been increasingly employed by other FPCs (Kinser, 2006).

Mindful of Phoenix's central position in for-profit higher education, this organizational exploration will employ a multi-frame analysis in an attempt to examine the University of Phoenix as an integral player in for-profit higher education. Such an analysis will provide entry points to improve for-profit higher education and better understand the sector's forward trajectory. The goal here is not to make definitive panacea-like prescriptions to remedy Phoenix or for-profit higher education or to make generalizations about the for-profit sector from an investigation of Phoenix, but rather to suggest basic theoretical avenues en route to better understanding and enhancing the for-profit sector going forward.

\section{STRUCTURAL FRAME ANALYSIS}

Bolman and Deal (2008) describe the activity of reframing as "looking at the same thing from multiple lenses or points of view," and consequently, when nothing seems to be working smoothly within an organization, reframing is a "tool for gaining clarity, regaining balance, generating new options, and finding strategies that make a difference" (p. 22). Structure has an important role within an organization as it dictates exchanges among internal players and external constituencies. Organizational structure can assume several configurations as evidenced by Mintzberg (1979) including rigidly hierarchical machine bureaucracies and more decentralized professional bureaucracies. Differentiation and integration are the elemental hallmarks of structural design.

Although Phoenix is clearly what Mintzberg (1979) would call a machine bureaucracy, with day-to-day operations being controlled by managers and standard procedures, efforts could be made by Phoenix executives and administrators to give more power to the teaching professionals who constitute the school's operating core. Like many for-profit educators, Phoenix instructors hold advanced degrees and occupy work positions outside the college that allow them to offer insight into real-world situations that students will face after graduation. These professionals could benefit from increased academic autonomy and a decrease in structural centralization; this would align them more closely with their not-for-profit educational colleagues. By virtue of the machine bureaucracy structure, Phoenix instructors may not have the power to make important curricular or admissions decisions. The centrally coordinated structure may potentially stifle instructor creativity and initiative on campus. In addition, institutional pressure placed upon faculty members to retain students may create a culture of fear where faculty will need to worry about losing their jobs if students do not attend or pass their courses (Field, 2011). This fear is one potential result of an overly rigid top-down structural model. Unlike decentralized professional bureaucracies at non-profit colleges and universities where the professional operating core has much more autonomy over their work, machine bureaucracies do not provide an optimal climate for instructors to thrive in. FPCs and their instructors may benefit from increased instructor input into curricular and admissions decisions.

\section{HUMAN RESOURCE FRAME ANALYSIS}

The human resource frame encompasses the idea that organizations "exist to serve human needs" since people and organizations need each other (Bolman \& Deal, 2008, p. 122). Ideally, organizations will benefit from satiating the needs of its customers. Students come to Phoenix hoping that the school will serve their needs for a 
convenient quality education. Executives at Phoenix need to address obstacles to graduation and career placement at their schools since a Phoenix degree will have very little value if it cannot open employers' doors after graduation.

Job placement is a complicated issue within the for-profit education sector. Students who manage to graduate are often met with employer resistance (Chait, 2011). This raises the question: How can FPCs enhance their profiles so that employers will be more likely to hire their graduates? This question does not have a simple answer. Name recognition will certainly play a role. Phoenix has become increasingly well known throughout the Unites States and thus employers may have some familiarity when looking at an applicant's Phoenix transcript.

Perhaps the most important student need that Phoenix satisfies next to convenience is that of respected accreditation. Shaw and London (2001) have shown us that a school's commitment to sustain a transfer function is determined by the ideological and cultural constructs that undergird a particular school (p. 92). Clearly Phoenix does not want to establish a transfer culture on campus because that would severely diminish profitability margins but most likely, it would not be able to do so even if a desire was there. Phoenix is accredited regionally which sets the school apart from the vast majority of its nationally accredited for-profit brethren. Earned credits from regionally accredited schools are more likely to transfer to traditional non-profit colleges allowing Phoenix students more peace of mind and educational flexibility. However, regional accreditation in the for-profit sector does not mean that credits earned at Phoenix will transfer to all non-profit colleges. Colleges have the right to reject and limit incoming credits for reasons they see fit and often credits accumulated at FPCs will not transfer. Although regional accreditation is the gold standard in academic credentialing and employers should take some comfort in knowing that a Phoenix education must adhere to the strict standards of a more comprehensive regional accrediting agency, students need to carefully research transfer guidelines at schools they wish to enter. As the for-profit education sector is held to increasingly stringent regulations, job-prospects and the transfer value of institutional credits may increase.

As the for-profit industry resets in accordance with new industry regulations, Phoenix is taking bold moves to increase corporate transparency. Some of the strategies that Phoenix is adopting include a free three-week required orientation for students who seek to enroll with fewer than 24 credits, financial literacy training to deter undue borrowing by students, and new recruitment strategies that pay much closer attention to the students they are enrolling (Blumenstyk, 2011). For example, Phoenix decided it would no longer enroll students who lack a high school diploma or GED but pass a basic entrance test. In terms of the orientation, students who fail to complete it cannot begin classes until they wait six months and take it again. In addition, Phoenix has a strict new policy against recruiter incentives. These strategies are likely to increase graduation rates, lower student loan default rates, and generally help boost the image of the school and sector.

\section{POLITICAL FRAME ANALYSIS}

From a political frame perspective, politics are at the heart of decision making. As Bolman and Deal (2008) explain, "politics is the realistic process of making decisions and allocating resources in a context of scarcity and divergent interests" (p. 190). Power is the most important asset at any organization as it carries the capacity to make things happen. At Phoenix, current political dynamics must be examined to the degree they undermine principles and ethics especially during difficult times. FPCs have traditionally competed for the attention of non-traditional students. As Susan VanDeventer Iverson (2007) has shown us, well-intentioned attempts to create a more inclusive campus may unintentionally reinforce practices that support exclusion and inequality. This brings us to debate the degree to which Phoenix and other FPCs may be hurting the underserved non-traditional students they are purporting to help. How can for-profit students possibly become upwardly mobile if they are not graduating or landing jobs that do not allow them to pay off their student loans? For-profit schools need to satisfy shareholders and other providers of investment capital in order to thrive. This is the economic reality at for-profit schools. However, there is corollary here that needs to be acknowledged by for-profit executives, namely, that in order to bring in more students, increase profitability margins, and drive up stock prices, a quality academic product needs to be offered. Phoenix should be applauded for responding with new policies aimed at enrolling students who are more likely to graduate and pay for their educational endeavors. The question of whether a for-profit college can balance the desire to make profits without exploiting their students will need to be continuously examined going forward. 


\section{SYMBOLIC FRAME ANALYSIS}

The symbolic frame focuses on "how humans make sense of the chaotic, ambiguous world in which they live" (Bolman \& Deal, 2008, p. 248). Humans attempt to make sense of the world through meaning, belief, and faith. Symbols are the root of meaning systems and often take the form of myths, visions, heroes, and ceremonies (Bolman \& Deal, 2008, p. 249). A symbolic discussion of Phoenix must start by looking at its founder, John Sperling. In every sense, Sperling is responsible for creating Phoenix's organizational saga, or a "collective understanding of unique accomplishment in a formally established group" (Clark, 1972, p. 178). Sperling's rebel spirit and desire to break away from traditional education and start an academic program for working adults provided the overarching symbolic inspiration for Phoenix (Bartlett, 2009). In many ways, Phoenix is a pointed response to the traditional non-profit educational sector. Mr. Sperling felt that working adults were not being catered to at the higher educational level. Phoenix was his attempt to change that. Sperling views Phoenix as a force for social good despite claims that for-profit education cannot have a true populist agenda (Berg, 2005).

Sperling grew up poor and was the victim of an abusive father. He managed to transcend his unfortunate childhood to successfully pursue a $\mathrm{PhD}$ in Economic History at the University of Cambridge. After teaching at several universities, Sperling felt unfulfilled as an academic. He wanted to work with underserved populations and create major reforms in higher education. His detractors felt that he would not be able to make a name for himself outside of his professorial duties. But, Sperling never listened to his detractors; his rebel spirit persisted (Bartlett, 2009).

What would become Phoenix grew out of a federally financed project to help juvenile delinquents and ended with Sperling becoming a self-made billionaire. Phoenix's us-against-the-world ethos is a direct result of its founder. One may argue the degree to which such an ethos has helped the school's image in recent years as Phoenix has grown at a pace that seemingly disregards the degree to which it is dwarfing the rest of the for-profit education sector. Recruiting violations cost Phoenix $\$ 10$ million in fines from the U.S. Department of Education and further lawsuits against the school are pending (Bartlett, 2009).

Phoenix has responded to symbolic challenges by launching a successful media campaign to put the face of their students and faculty in front of the world (Blumenstyk, 2011). This "I am a Phoenix" campaign is likely to go a long way in terms of humanizing the school to the masses and attracting students. In addition, media spots can help Phoenix convey the idea that it is not simply an online school, but a school with many brick and mortar campuses nationally. In particular, employers will gain a more positive image of the school after learning how successful Phoenix graduates have been over the years.

\section{CONCLUSION}

In conclusion, an analysis has been put forth detailing the important role the University of Phoenix has played and can continue to play in (re)defining higher education in the United States. As the largest provider of higher education in the United States, Phoenix holds a distinct position in the higher education landscape. As the leader in for-profit higher education, the school can set an example and become the model for how proprietary education can be a positive force in the world. Recent policy responses to federal regulations will likely position the school to prosper.

Reframing constructs, respectively, shed light on the various ways Phoenix can potentially represent and deviate from the rest of the for-profit sector going forward. Structurally, Phoenix might benefit from transcending the rigid simplicity of a machine bureaucracy. From a human resource perspective, the needs of students should be addressed and satiated without a large degree of internal conflict. Politically, Phoenix has responded to new regulations with policies aimed at enrolling students who are more likely to graduate and pay for their educational endeavors. Symbolically, the rebel spirit of founder John Sperling underpins Phoenix; Sperling's desire to make higher education more accessible to working adults is embodied in everything the school does. As the for-profit sector faces new challenges in the form of impending federal regulations and varying degrees of customer skepticism, the University of Phoenix will undoubtedly lead the push to legitimize the for-profit education sector as a worthy and respected alternative to traditional non-profit education. All for-profit institutions of higher education 
can benefit from reframing activities which can ultimately provide for-profit leaders with important insight necessary to enhance working and learning environments on campus.

\section{AUTHOR INFORMATION}

Matthew R. Hodgman is a PhD student in Higher Education Management at the University of Pittsburgh. Previously, Mr. Hodgman served as an adjunct professor of general education at Westwood College and currently serves as an adjunct professor of English at Goodwin College. He holds degrees from Georgetown, Johns Hopkins, West Virginia University, George Washington, and the University of Pennsylvania. E-mail: mhodgman@goodwin.edu.

\section{REFERENCES}

1. $\quad$ Bartlett, T. (2009, July 10). Phoenix risen. Chronicle of Higher Education, 55(41), A1-A13.

2. Berg, G. A. (2005, May/June). Reform higher education with capitalism? Change, 37(3), 28-34.

3. Blumenstyk, G. (2011, February 11). Fast growing U. of Phoenix calculates a more careful course.

Chronicle of Higher Education, 57(23), A1-A16.

4. $\quad$ Bolman, L. G., \& Deal, T.E. (2008). Reframing organizations: Artistry, choice, and leadership. San Francisco: Jossey-Bass.

5. $\quad$ Chait, J. (2011, March 24). The diploma factories. New Republic, 242(4), 2-2.

6. Clark, B. R. (1972, June). The organizational saga in higher education. Administrative Science Quarterly, $17(2), 178-184$.

7. Field, K. (2011, May 13). Faculty at for-profits allege constant pressure to keep students enrolled. Chronicle of Higher Education, 57(36), A1-A12.

8. $\quad$ For-profit educator to pay $\$ 67.5$ million settlement. (2009, December 15). Wall Street Journal, p. B4.

9. Gavett, G. (2011, August 24). For-profit college enrollment drops sharply. PBS Frontline. Retrieved from http://www.pbs.org/wgbh/pages/frontline/education/college-inc/for-profit-college-enrollment-dropssharply/

10. Hacker, A., \& Dreifus, C. (2010). Higher education?: How colleges are wasting our money and failing our kids-and what we can do about it. New York: St. Martin's Griffin.

11. Iverson, S.V. (2007, December). Camouflaging power and privilege: A critical race analysis of university diversity politics. Educational Administration Quarterly, 43(5), 586-611.

12. Kinser, K. (2006, July/August). What Phoenix doesn't teach us about for-profit higher education. Change, 38(4), 24-29.

13. Liu, M. C. (2011, June). Do for-profit schools pass the test? State Legislatures, 37(6), 15-17.

14. Mintzberg, H. (1979). The structuring of organizations: A synthesis of the research. Englewood Cliffs, NJ: Prentice-Hall.

15. Shaw, K. M., \& London, H. B. (2001, Fall). Culture and ideology in keeping transfer commitment: Three community colleges. The Review of Higher Education, 25(1), 91-114.

16. Stanley, T. (2010, October 12). On for-profit colleges, Congress gets schooled-again. The New Republic. Retrieved from http://www.tnr.com/blog/jonathan-cohn/78333/profit-colleges-congress-gets-schooledagain

17. Wilson, R. (2010, February 12). For-profit colleges change higher education's landscape. Chronicle of Higher Education, 56(22), A1-A19.

18. Yeoman, B. (2011, May/June). The high price of for-profit colleges. Academe, 97(3), 32-37. 


\section{NOTES}

